\title{
Power Quality Evaluation for Electrical Installation of Hospital Building
}

\author{
Agus Jamal $^{1}$, Sekarlita Gusfat Putri ${ }^{2}$, Anna Nur Nazilah Chamim ${ }^{3}$, Ramadoni Syahputra ${ }^{4}$ \\ Department of Electrical Engineering, Faculty of Engineering \\ Universitas Muhammadiyah Yogyakarta \\ Yogyakarta, Indonesia
}

\begin{abstract}
This paper presents improvements to the quality of power in hospital building installations using power capacitors. Power quality in the distribution network is an important issue that must be considered in the electric power system. One important variable that must be found in the quality of the power distribution system is the power factor. The power factor plays an essential role in determining the efficiency of a distribution network. A good power factor will make the distribution system very efficient in using electricity. Hospital building installation is one component in the distribution network that is very important to analyze. Nowadays, hospitals have a lot of computer-based medical equipment. This medical equipment contains many electronic components that significantly affect the power factor of the system. In this study, power quality analysis has been carried out on the building installation of one of the largest hospitals in Yogyakarta, Indonesia. In the initial condition, the power losses at the facility were quite high. Installation of power capacitors in these installations can improve the power factor, and ultimately improve the performance of the electrical installation system in the hospital building.
\end{abstract}

Keywords-Power quality; power capacitor; hospital building; electrical installation

\section{INTRODUCTION}

The estimated electricity demand is calculated based on the intensity of the need for electricity usage. With the addition of an ever-increasing amount of load, it must be followed by reliable supply and excellent quality electricity services by maintaining the quality of the system voltage [1][3]. In the distribution of electricity from electric power sources to consumers who are located far apart, there will be losses in the form of power losses and voltage losses. The amount of power losses and voltage losses on the distribution channel depends on the type and length of the conduit, the kind of distribution network, the capacity of the transformer, the kind of load, the power factor, and the amount of installed power and the number of inductive loads that cause an increase in demand reactive power [4]-[6].

Reduced electrical power, followed by a large number of systems that use energy, will result in not optimal performance of each component and will cause several problems faced, including high line current, low power factor, and power losses [7]-[9]. The load contained in the distribution network can be either capacitive or inductive, but in general, it is an inductive load. If the inductive and capacitive reactive loads get higher, it will increase the current, increase the power losses, and reduce the power factor [10].
Considering how vital electrical energy services are to consumers, good quality electricity is needed [11]. There are several methods to correct the voltage drop in a system, namely by increasing the cross-section wire, changing the feeder section from one phase to a three-phase system, sending the load through a new feeder. The three methods above show ineffectiveness both in terms of infrastructure and in terms of cost. Another technique that allows for more productive work is by using a Bank Capacitor [12].

The addition of capacitor banks can improve the power factor, supply reactive power so that it can maximize the use of complex power, reduce voltage drops, avoid overloaded transformers, provide additional power available, save efficiency, can cause current to flow in the conductor to be small, so as to reduce the magnitude of power losses so as to improve the power factor, and bank capacitors can also reduce other losses on electrical installations [13]-[14].

Besides, along with the advancement in electrical appliances, more and more electrical equipment is included in the non-linear loads. Besides being practical, non-linear loads are also easy to operate, so that non-linear loads are widely used. Non-linear loads are generally made of semiconductor materials and electronic elements that can produce harmonics in an electric power system.

Related to previous studies concerning harmonics concluded that the harmonic component could cause an increase in power losses because harmonics is an event produced by the use of non-linear loads on the electric power system. This incident can cause problems in terms of power quality, which will eventually result in various kinds of losses and damage to some electrical equipment [15].

Therefore calculating the need for capacitors and harmonic distortion in the conductor can help reduce power losses. Voltage decreases typically occur at the end of the line, and voltage regulation worsens and can also minimize damage to electrical equipment due to the presence of harmonic distortion that can cause harm to both producers, in this case, PLN as the electricity provider and consumer. Based on the background of the problems above, the authors are compelled to research on improving the quality of electric power in hospital buildings using active filters. 


\section{POWER QUALiTy IN HOSPITAL BUILDING INSTALLATION}

Along with the times, the need for electricity consumption will continue to increase. Therefore, improvement in the quality and quantity of electrical energy is one of the reasons why utility companies need to pay attention to the issue of electric power quality. Attention to the issue of the quality of electric power in industrial consumers who need supplies because the machines in the industry are sensitive to surge or voltage instability. Therefore it is necessary to try an electrical distribution system that can provide services that meet the criteria desired by consumers [16].

Since the late 1980s, the quality of electric power has become an important issue in the industry. The quality of electric power is a picture of the pros and cons of an electricity system in dealing with disturbances that might occur in the system [17]-[19].

Four main reasons for the need for more attention to power quality issues [20]:

1) Electrical devices used today are very sensitive to the quality of electrical power, where microprocessor-based devices and other power electronics require stable voltage service, and voltage levels must also be maintained.

2) The emphasis is on the overall power efficiency of the electrical system, which results in continued growth in highefficiency equipment applications, such as regulating the speed of the electric motor and the use of bank capacitors for power factor correction to reduce losses. This increases the level of harmonics in the power system and can reduce the quality of power.

3) Increased consumer awareness of power quality problems, where consumers become more aware of problems such as interruptions, sags, and transient switching and expect electrical utilities to improve the quality of power delivered.

4) The electric power system currently has a lot of interconnection between networks, which gives a consequence that the failure of each component will fail other components.

Poor power quality can cause problems in the power system in the form of problems with surges or large voltage changes, high currents, and frequencies that will cause failure or damage to the equipment where this failure can damage electrical equipment both on the sending and receiving sides. Therefore to anticipate losses that can occur both from the PLN and consumers, the PLN must strive for a good electrical system.

\section{A. Electric Power}

Electric power is the energy expended to do business. In an electric power system, power is the amount used to do work or business. Power has units of Watt, which is the product of voltage (volts) and currents (amperes). Electric power is stated in $\mathrm{P}$, the electric voltage is expressed in $\mathrm{V}$, and the electric current is expressed in I, so the amount of electric power is expressed in [18]:

$\mathrm{P}=\mathrm{V} \mathrm{I} \operatorname{Cos} \varphi$
Active power is the power that is used to carry out actual energy. The active power unit is watts. The active power equation is as follows [6]:

For three phases $(\mathrm{P})=\mathrm{V} I \operatorname{Cos} \varphi$

For thirteen phases $(\mathrm{P})=\sqrt{ } 3 \mathrm{~V}$ I $\operatorname{Cos} \varphi$

This power is commonly used by consumers and is converted in the form of work.

Reactive power is the amount of power required for the formation of a magnetic field. From the structure of the magnetic field, magnetic field flux will form. Examples of power that cause reactive power are transformers, motors, and others. The unit of reactive power is Var. The reactive power equation is as follows [6]:

For one phase $\mathrm{Q}=\mathrm{V}$ I $\operatorname{Sin} \varphi$

For three phases $Q=\sqrt{ } 3 \mathrm{~V}$ I $\operatorname{Sin} \varphi$

Apparent power is the power produced by the multiplication of voltage and current in a network. The apparent power unit is VA. The equation in active power is as follows [6]:

For one phase $\mathrm{S}=\mathrm{V}$ I

For three phases $S=\sqrt{ } 3 \mathrm{~V}$ I

The power triangle is a triangle that describes the mathematical relationship between apparent power, active power, and reactive power based on the principle of trigonometry.

\section{B. Power Factor}

The power factor $(\operatorname{Cos} \varphi)$ is the ratio between active power (Watt) and real power (VA) used in an AC circuit or phase angle difference between $\mathrm{V}$ and I which is usually expressed in $\cos \varphi[6]$.

Power Factor $=$ Active Power $(\mathrm{P}) /$ Apparent Power $(\mathrm{S})$

$=\mathrm{kW} / \mathrm{kVA}$

$=\mathrm{VI} \operatorname{Cos} \varphi / \mathrm{V} \mathrm{I}$

$=\operatorname{Cos} \varphi$

Lagging power factor is a state in which the current power factor has the following conditions; load or electrical equipment requires reactive power from the system, or the load is inductive, and the voltage $(\mathrm{V})$ precedes I with an angle $\varphi$ resulting in a backward current (I) from the source.

Leading power factor is a state when the power factor has the following conditions; loads or electrical equipment provide reactive power from the system or capacitive loads, and the voltage (V) is backward from the current with an angle $\varphi$ which results in the current passing the voltage.

The power factor has a range between $0-1$ and is expressed as a percent (\%). A good power factor is when the value of the power factor is close to one. 
Tan $\varphi=$ Reactive Power (Q) / Active Power (P)

$=\mathrm{kVAR} / \mathrm{kW}$

Active power generally has a fixed value, while the values of apparent power (kVA) and reactive power (kVAR) have values that vary according to the value of the power factor [6].

Reactive Power $(\mathrm{Q})=$ Active Power $(\mathrm{P}) \times \operatorname{Tan} \varphi$

To improve the power factor, the formula for calculating the required capacitor rating is as follows [6],

Reactive power at initial pf $=$ Active Power $(\mathrm{P}) \times \operatorname{Tan} \varphi_{1}$

Reactive power improved $\mathrm{pf}=$ Active Power $\mathrm{x} \operatorname{Tan} \varphi_{2}$

The capacitor ratings needed to improve the power factor are [6]:

Reactive Power $=$ Active Power $\mathrm{x}\left(\operatorname{Tan} \varphi_{1}-\operatorname{Tan} \varphi_{2}\right)$

Increasing the power factor will have several advantages, including:

a) The electricity bill becomes smaller (PLN will give a fine if the pf value is below 0.85).

b) The distribution capacity of the electric power system will increase.

c) Reducing power losses in the system.

d) Increasing the voltage will minimize the voltage drop that occurs in the electric power system.

If the pf value is less than 0.85 , the active power capacity $(\mathrm{kW})$ used will decrease because the smaller the pf value, the reactive power value is higher.

\section{Harmonics in Electrical Installation System}

In the electric power system, there is a phenomenon called harmonics, in which the current waveform or voltage from the supply will be distorted so that it can cause damage to electrical equipment. Another definition of harmonics is the phenomenon of the formation of waves with different frequencies, which are multiplications of integers with their fundamental frequencies. The electric power system is designed to operate at frequencies of $50 \mathrm{~Hz}$ or $60 \mathrm{~Hz}$, but in reality, several loads cause the appearance of currents and voltages with frequencies above $50 / 60 \mathrm{~Hz}$. Loads whose frequency capacity exceeds a predetermined capacity are called non-linear loads. Whereas $50 \mathrm{~Hz}$ or $60 \mathrm{~Hz}$ frequencies are called fundamental frequencies, and multiples are called harmonics or harmonics.

An electric power system has a fundamental frequency of $50 \mathrm{~Hz}$, so for both frequencies, it is a wave with a frequency of $100 \mathrm{~Hz}$, the third harmonic is a wave with a frequency of $150 \mathrm{~Hz}$, and so on. In an electrical system, harmonics are currents and voltages that are distorted and deviate from the sinusoidal waveform. Periodic distortion of sine waves of current, voltage, or power with a waveform is multiple outsides of one of the fundamental frequencies. The system is designed to operate at $50 \mathrm{~Hz}$ or $60 \mathrm{~Hz}$. These waves then hitch a ride on pure or original waves so that a defective wave is formed, which is the sum between the instantaneous pure wave and the harmonic wave, as shown in Fig. 1.
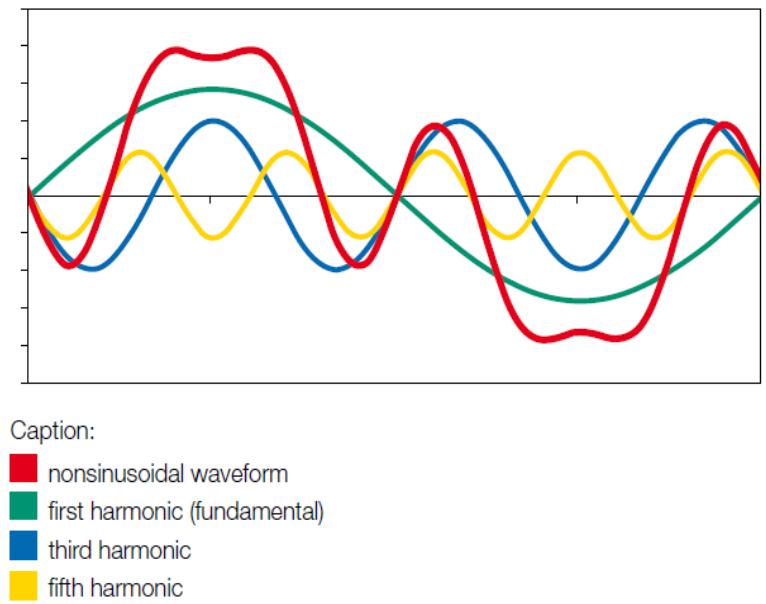

Fig. 1. Harmonic Waveform.

In 1916 Steinmetz first examined the harmonic phenomenon in the electric power system. Steinmetz observed the $3 \mathrm{rd}$ harmonic that appeared in the 3 phase system. The $3 \mathrm{rd}$ harmonic is caused by the saturation of the iron core in the transformer and electric machines. In 1930-1940, the 3rd order harmonic problem was resolved well. But in this day and age, electronic device's power is the cause of the appearance of harmonics [20].

Power electronic circuits are widely used in switching power supplies, UPS, computers, printers, fluorescent lamps, and other equipment. The reason many parties use power electronics is that it is efficient and easy to control, but this device can draw non-sinusoidal AC currents from an AC source. When this current acts with system impedance, it will generate harmonic voltage and current. Voltage and current harmonic waves move as if they were against the direction of the voltage and current coming from the source. If this harmonic wave joins with its fundamental wave, then the fundamental wave will experience distortion and change its shape to an imperfect sinusoidal wave.

Harmonic is an event that takes place periodically, and in the form of a steady-state, the existence of continuous harmonics can cause distortion in the sine wave voltage and current and will adversely affect the system or electrical equipment. The distortion signal itself is the sum of several harmonics together.

All equipment that is connected to a system that contains harmonics will have different effects. The equipment experiencing a decrease in performance or can also be damaged and will also influence the power quality of the electric power system. This harmonic distortion can disrupt or increase the workload of tools connected to the same network. Some things that can be caused by harmonics are as follows:

- It causes increased heating and losses at switchgear, thereby reducing the ability to flow current and shorten the life of some insulator components.

- The emergence of mechanical vibrations in electrical panels which are mechanical resonance vibrations due to harmonics of high-frequency currents. 
- Harmonics can cause additional torque on kWh-meters of an electromechanical type that uses a rotating induction disk. As consequently, the disk rotation will be faster, or there is a measurement error on the $\mathrm{kWh}$ meter because the induction disk is designed only to operate at a fundamental frequency.

- Reduces the life of the transformer, decreases efficiency in generator power, transmission, and usage

- The working temperature of the equipment is also getting higher and will eventually reduce the life of the equipment. Also, increasing losses will reduce equipment efficiency.

- Damage to the power factor correction tool (capacitor bank).

Harmonics are the formation of waves, which are multiples of fundamental frequencies [21]. Voltage and current waves, which were originally pure sinusoidal, will be distorted to no longer pure sinusoidal. The index is called THD (Total Harmonic Distortion), where THD is a comparison of the value of fundamental components that are usually in the form of a percent (\%). In general, THD is used to determine the type of current and voltage waveform deviations that contain harmonics against the original sine wave every one period.

The difference between $\mathrm{THD}_{\mathrm{V}}$ and $\mathrm{THD}_{\mathrm{I}}$ is if $\mathrm{THD}_{\mathrm{V}}$ is to determine the quality of the voltage from the source, while at $\mathrm{THD}_{\mathrm{I}}$ to assess the quality of the current from the load. In general, the cause is designed to flow the voltage close to the original sine so that the THD value of the allowable voltage is much smaller than $\mathrm{THD}_{\mathrm{I}}$. The danger that $\mathrm{THD}_{\mathrm{I}}$ can cause is overheating. However, the presence of abundant current harmonics will create a high $\mathrm{THD}_{\mathrm{V}}$.

The level of harmonic interference in the electric network reflects the distortion factor that exists in the electrical power system. One measurement that is generally used is THD that will be used in this study, for voltage or current.

The basic concept of the filter current is:

Filter Current $=$ Fundamental Flow - Load Current

From the formulation above, it is found that the filter current is the fundamental current multiplied by THD [22]:

$\mathrm{I}_{\text {filter }}=\mathrm{I}_{1} \times \mathrm{THD}_{\mathrm{I}}(\%)$ [22]:

With a Safety Factor of $20 \%$ we get the following equation

$\mathrm{I}_{\text {filter }}=\mathrm{I}_{\mathrm{RMS}} \mathrm{X} \frac{\sqrt{T H D(I)^{2}(\%)}}{T H D(I)^{2}(\%)+100^{2}} \times \mathrm{FS}$

Voltage, $\mathrm{THD}_{\mathrm{V}}=\frac{\sqrt{\sum_{h>1}^{N} V^{2} h}}{V_{1}}$

Current, $\operatorname{THD}_{\mathrm{I}}=\frac{\sqrt{\sum_{h>1}^{\infty} I^{2} h}}{I_{1}}$
Equations (18) and (19) are equations used to express the THD values of current and voltage.

\section{Maintaining the Integrity of the Specifications}

The template is used to format your paper and style the text. All margins, column widths, line spaces, and text fonts are prescribed; please do not alter them. You may note peculiarities. For example, the head margin in this template measures proportionately more than is customary. This measurement and others are deliberate, using specifications that anticipate your paper as one part of the entire proceedings, and not as an independent document. Please do not revise any of the current designations.

\section{METHODOLOGY}

This study discusses energy audits and their mitigation efforts. The object of this study is a hospital building, which is a multi-story building that has a very complicated electrical installation, where the electrical loads are complete medical devices. The hospital building is located in an area in the city of Yogyakarta, the province of Yogyakarta Special Region, Indonesia.

The rare steps of this research are shown in Fig. 2.

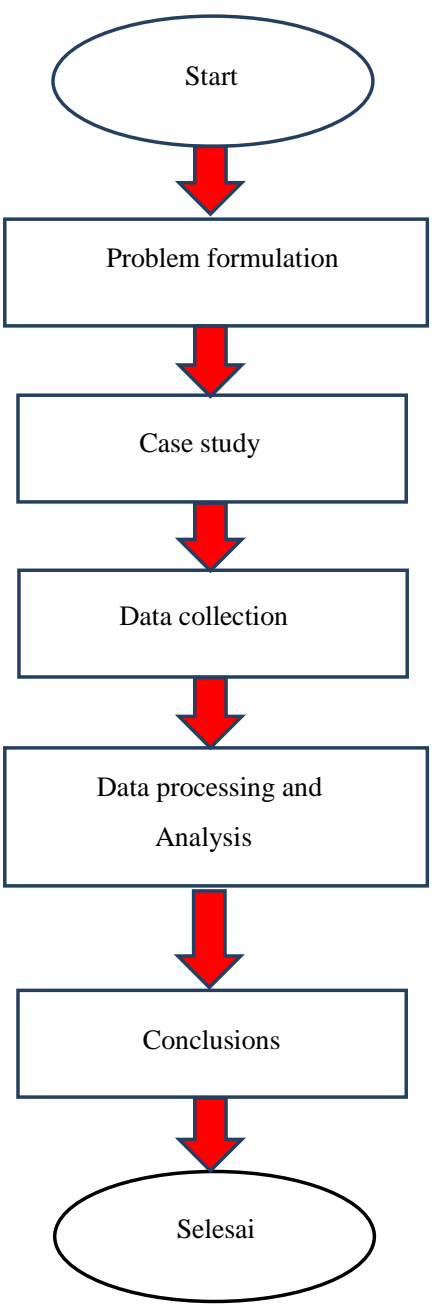

Fig. 2. The Steps of this Research. 
Based on the data obtained by various sources, the data is processed by calculation according to standard procedures. The estimate of the value of the bank capacitors and the harmonic distortion obtained is then analyzed so that it can be seen how much the capacity of the capacitor of the bank and what percentage of the harmonic distortion. The next step is data processing, which is done by ETAP (Electric Transient and Analysis Program) software. The modeling method in ETAP is software that supports the electric power system. This device is capable of working offline for electric power simulations, online for real-time data management or used to control the order in real-time.

\section{RESULTS AND DISCUSSION}

\section{A. Electric Energy Audit on Hospital Electrical Installations}

Before analyzing data calculations, the thing to do is first to know what data is needed in the forecast that will be done. The LVMDP (Low Voltage Medium Distribution Panel) schedule is the central panel after the transformer is in the leading powerhouse, containing the main MCCB (Molded Case Circuit Breaker) of the building. Data on LVMDP measurement results at hospital electrical installations are shown in Table I.

\section{B. Modeling in ETAP Software}

After knowing the entire load data installed in the hospital building then the design of the load is carried out, as shown in
Fig. 3. This design is carried out in ETAP 12.6.0 software by entering the load data in Table I. This software can simulate in an offline state and can analyze data such as voltage drops, current flowing at load, active, reactive, and apparent power. In Fig. 3, you can see modeling on the PLN power source using the toolbar power grid. The power grid in ETAP is an ideal voltage source in the sense of being able to supply power with a fixed voltage even though the energy absorbed is changing. For loads that do not contain non-linear loads using static loads, static loads in ETAP are loads that do not provide many electric motors. Then for loads that contain lots of electric motors, use a lumped load. Fig. 4 shows modeling LVMDP load on ETAP before installing power capacitors for calculation of electric current and apparent power.

Fig. 3 and Fig. 4 are modeling as well as simulating the calculation of active power $(\mathrm{kW})$, recative power (kVAR), apparent power (kVA), current and also the voltage that exists at the hospital electrical installation load before installing a capacitor bank using ETAP 12.6.0 software. At the time before using capacitors, the apparent power at the voltage source and transformer is large enough and the current flowing is quite large. The greater the current flowing, the more heat the cable can cause to decrease the life of the cable and can also damage other protection components. Measurement data before installation of power capacitors was shown in Table II.

TABLE. I. DATA ON LVMDP MEASUREMENT RESUltS AT HoSPITAL ELECTRICAL INSTALLATIONS

\begin{tabular}{|c|c|c|c|c|c|c|c|c|c|c|c|c|c|}
\hline \multirow[b]{2}{*}{ NO } & \multirow[b]{2}{*}{ PANELS } & \multirow[b]{2}{*}{ LOCATION } & \multicolumn{5}{|c|}{ LOAD CAPACITY } & \multirow[b]{2}{*}{$\mathrm{PF}(\%)$} & \multicolumn{5}{|c|}{ NORMAL LOAD } \\
\hline & & & $\begin{array}{l}S \\
(\text { KVA) }\end{array}$ & $\begin{array}{l}\mathrm{P} \\
(\mathrm{KW})\end{array}$ & $\mathrm{I}_{\mathrm{R}}(\mathrm{kA})$ & $\mathrm{I}_{\mathrm{S}}(\mathrm{kA})$ & $\mathrm{I}_{\mathrm{T}}(\mathrm{kA})$ & & $\begin{array}{l}\text { S } \\
\text { (KVA) }\end{array}$ & $\begin{array}{l}\mathrm{P} \\
(\mathrm{KW})\end{array}$ & $\mathrm{I}_{\mathrm{R}}(\mathrm{kA})$ & $\mathrm{I}_{\mathrm{S}}(\mathrm{kA})$ & $\mathrm{I}_{\mathrm{T}}(\mathrm{kA})$ \\
\hline 1 & SDP EMERGENCY & Rooftop & 145.8 & 105.0 & 220.9 & 220.9 & 220.9 & 0.5 & 66.0 & 44.3 & 100.1 & 100.1 & 100.1 \\
\hline 3 & LP.B.3 & Basement 3 & 8.1 & 6.9 & 12.6 & 11.8 & 12.6 & 0.7 & 5.7 & 4.8 & 8.8 & 8.2 & 8.8 \\
\hline 4 & LP.B. 2 & Basement 2 & 6.4 & 5.4 & 10.0 & 9.5 & 9.6 & 0.7 & 4.5 & 3.8 & 7.0 & 6.6 & 6.7 \\
\hline 5 & LP.B.1 & Basement 1 & 7.2 & 6.1 & 10.9 & 11.3 & 10.7 & 0.7 & 5.1 & 4.3 & 7.6 & 7.9 & 7.5 \\
\hline 7 & LP.LG & Lower Ground & 11.7 & 10.0 & 17.6 & 17.4 & 18.4 & 0.7 & 8.2 & 7.0 & 12.3 & 12.2 & 12.9 \\
\hline 8 & PP.LG & Lower Ground & 45.6 & 38.8 & 67.9 & 70.9 & 68.4 & 0.7 & 31.9 & 27.1 & 47.5 & 49.6 & 47.9 \\
\hline 9 & PP.LAB & Lower Ground & 52.8 & 42.2 & 80.0 & 80.0 & 80.0 & 0.7 & 37.0 & 29.6 & 56.0 & 56.0 & 56.0 \\
\hline 10 & PP.RADIOLOGY & Lower Ground & 320.0 & 256.0 & 484.8 & 484.8 & 484.8 & 0.5 & 160.0 & 128.0 & 242.4 & 242.4 & 242.4 \\
\hline 11 & PK.ESCALATOR 1 & Ground floor & 16.9 & 11.0 & 25.6 & 25.6 & 25.6 & 1.0 & 16.9 & 11.0 & 25.6 & 25.6 & 25.6 \\
\hline 12 & PK.ESCALATOR 2 & Ground floor & 16.9 & 11.0 & 25.6 & 25.6 & 25.6 & 0.75 & 12.7 & 8.3 & 19.2 & 19.2 & 19.2 \\
\hline 16 & PP.1 & Floor 1 & 24.8 & 21.1 & 37.7 & 36.1 & 39.0 & 0.7 & 17.4 & 14.8 & 26.4 & 25.3 & 27.3 \\
\hline 17 & LP. 2 & Floor 2 & 6.7 & 5.7 & 9.9 & 11.1 & 9.3 & 0.7 & 4.7 & 4.0 & 6.9 & 7.8 & 6.5 \\
\hline 18 & PP.2 & Floor 2 & 26.9 & 22.9 & 41.2 & 41.4 & 39.6 & 0.7 & 18.8 & 16.0 & 28.8 & 29.0 & 27.7 \\
\hline 19 & PP.KEMOTERAPI & Floor 2 & 7.7 & 6.6 & 12.8 & 11.2 & 11.0 & 0.7 & 5.4 & 4.6 & 9.0 & 7.9 & 7.7 \\
\hline 20 & LP. 3 & Floor 3 & 6.0 & 5.1 & 9.0 & 9.5 & 8.8 & 0.7 & 4.2 & 3.6 & 6.3 & 6.6 & 6.2 \\
\hline 21 & PP.3 & Floor 3 & 34.8 & 29.6 & 52.7 & 52.9 & 52.4 & 0.7 & 24.3 & 20.7 & 36.9 & 37.1 & 36.7 \\
\hline 22 & LP.4 & Floor 4 & 26.3 & 29.6 & 40.1 & 39.6 & 39.6 & 0.7 & 18.4 & 20.7 & 28.1 & 27.7 & 27.8 \\
\hline 23 & SDP.ATAP & Rooftop & 17.9 & 13.5 & 27.5 & 27.5 & 26.4 & 0.7 & 12.6 & 9.6 & 19.4 & 19.4 & 18.5 \\
\hline 24 & PP.PH & Power House & 1.6 & 1.4 & 3.5 & 2.7 & 1.3 & 0.7 & 1.1 & 0.98 & 2.5 & 1.9 & 1.0 \\
\hline \multicolumn{3}{|c|}{ Total } & 1946,3 & 1433,3 & 1946.3 & 1433.3 & 2957.9 & 2946.9 & 2942.4 & & 1352.8 & 982.7 & 2056.4 \\
\hline
\end{tabular}



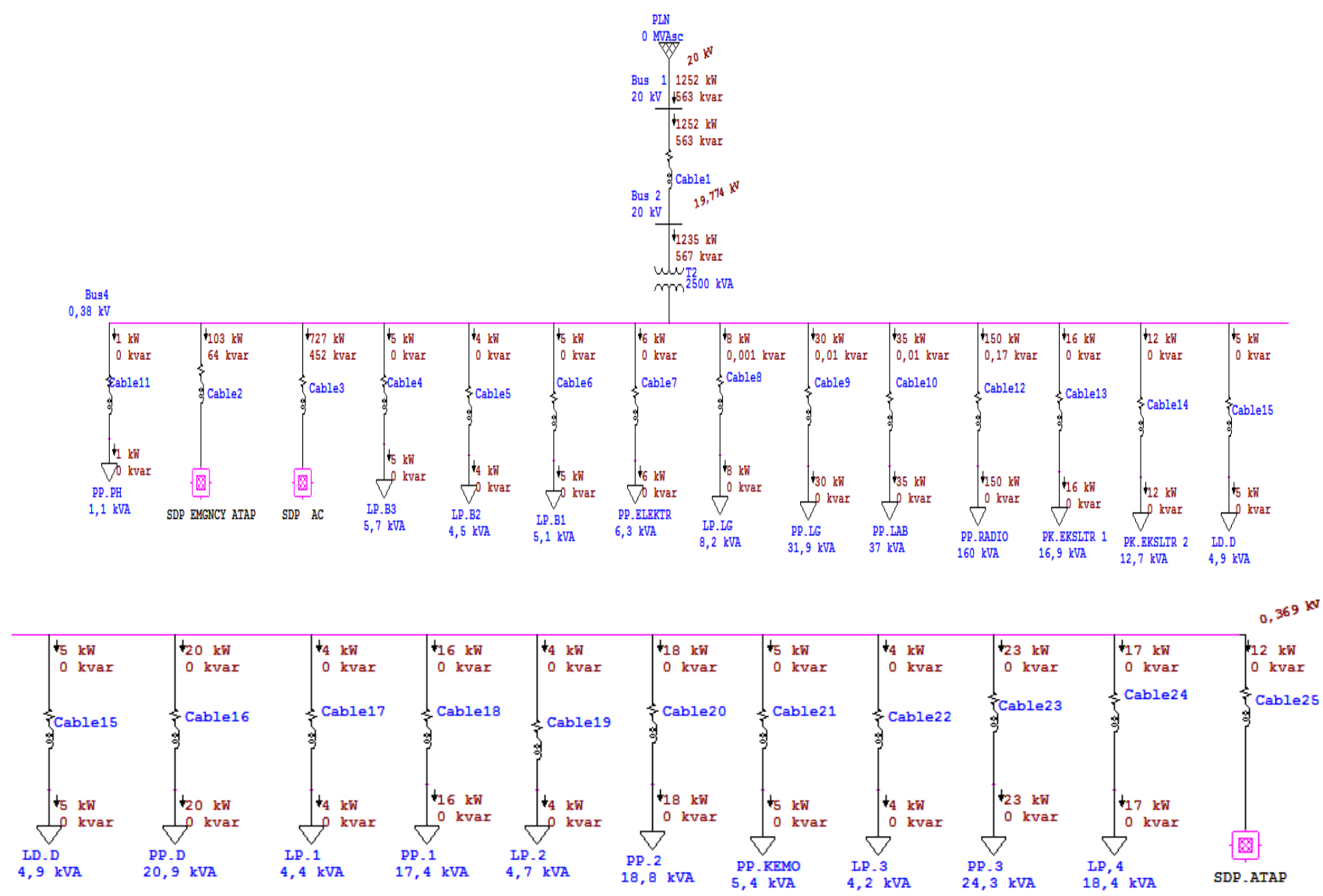

Fig. 3. Modeling LVMDP Load on ETAP before Installing Power Capacitors for Calculation of Active and Reactive Power.
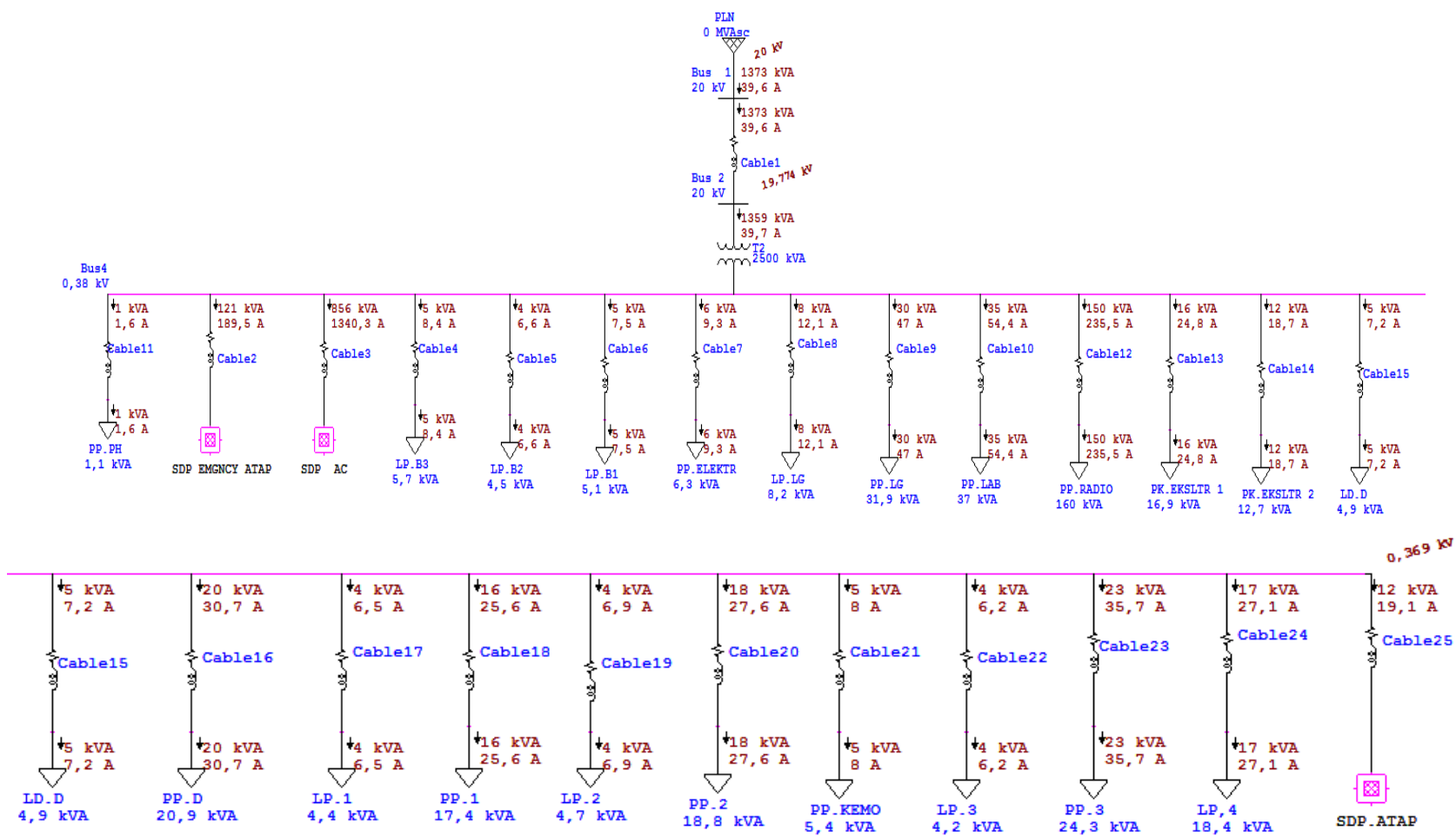

Fig. 4. Modeling LVMDP Load on ETAP before Installing Power Capacitors for Calculation of Electric Current and Power. 
TABLE. II. MEASUREMENT DATA BEFore InStALlation OF POWER CAPACITORS

\begin{tabular}{|c|c|c|c|c|c|c|}
\hline \multirow{2}{*}{ No. } & \multirow{2}{*}{ Components } & \multirow{2}{*}{ Voltage (kV) } & \multicolumn{3}{|l|}{ Power } & \multirow{2}{*}{$\begin{array}{l}\text { Electric Curents } \\
\text { (A) }\end{array}$} \\
\hline & & & $\mathrm{P}(\mathrm{kW})$ & $\mathrm{Q}$ (kVAR) & $\mathrm{S}(\mathrm{kVA})$ & \\
\hline 1. & Busbar $20 \mathrm{kV}$ & 20 & 1252 & 563 & 1373 & 39,6 \\
\hline 2. & Busbar 0,38 kV & 0,369 & 1235 & 567 & 1359 & 39,7 \\
\hline 3. & Busbar SDP Emergcny & 0,368 & 103 & 64 & 121 & 189,5 \\
\hline 4. & Busbar SDP AC & 0,365 & 727 & 452 & 856 & 1340,3 \\
\hline 5. & Busbar SDP Atap & 0,368 & 12 & 0 & 12 & 19,1 \\
\hline
\end{tabular}

After knowing the needs of the bank capacitors with the desired cos phi fix from 0.7 to 0.9 through calculations, then a simulation of the use of the bank capacitors on the distribution channel. Installation of bank capacitors using the Global Compensation method, namely, the installation of bank capacitors on the main panel, has been recommended. This method serves to be able to receive more active power needed. Fig. 5 and Fig. 6 show the modeling of the placement of capacitor banks in the electrical insulating system of a hospital building.

Reactive power on the side of the voltage source and transformer decreases, and active power increases from the state before the capacitor is installed. Because the function of installing capacitors with the global compensation method is to reduce the supply of the transformer, thus the electricity load will be able to receive more active power needed and reduce the power tariff for excess kVAR consumption.

Fig. 5 and Fig. 6 show the LVMDP load scheme with a simulation of apparent power calculation $(\mathrm{kVA})$ and the current flowing. Both images show installation when using capacitors. The apparent power available at the voltage source and transformer is reduced from the state before using the capacitor bank. Based on the report data from the ETAP 12.6.0 simulation, where the $20 \mathrm{kv}$ PLN voltage source goes to the loads that exist in the hospital installation, it can be seen that the ratio of losses and power factors as shown in Table III.

Based on Table III, it can be concluded that the effect of the use of bank capacitors on hospital installations can reduce power losses as evidenced by a decrease in active power losses of $3.0 \mathrm{~kW}$. The results of the comparison of the amount of active power, reactive power and apparent power before and after the installation of capacitors are as in Table IV.

In Table IV, it can be seen that all observed variables have improved with the installation of power capacitors in hospital building installations in Yogyakarta, Indonesia. These variables are the system voltage, which has developed a profile, and the electric current has decreased. This condition makes the power losses smaller. Variable active power, reactive power, and apparent power measurement results after the installation of power capacitors also improved.

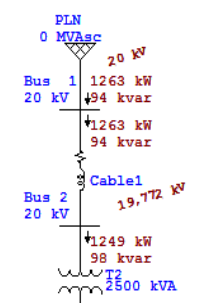

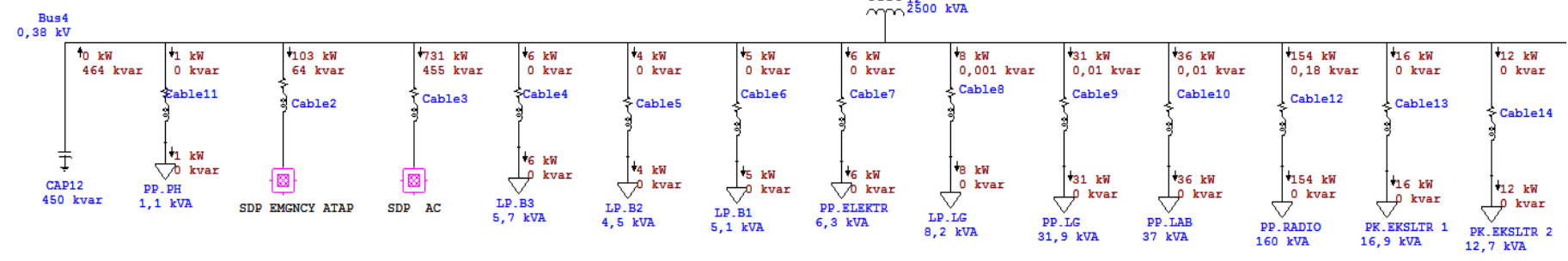
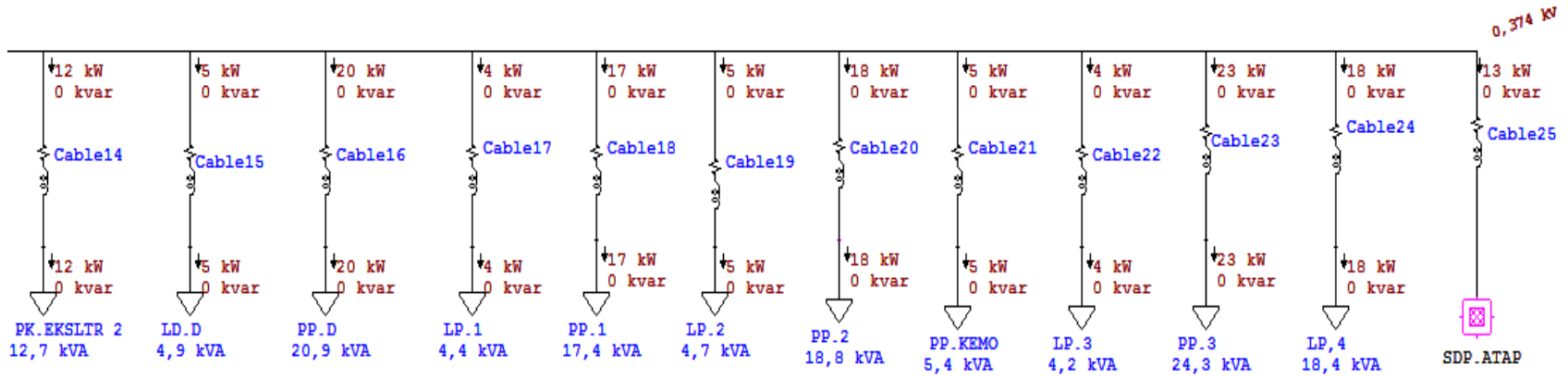

Fig. 5. Modeling LVMDP Load on ETAP after Installing Power Capacitors for Calculation of Active and Reactive Power. 


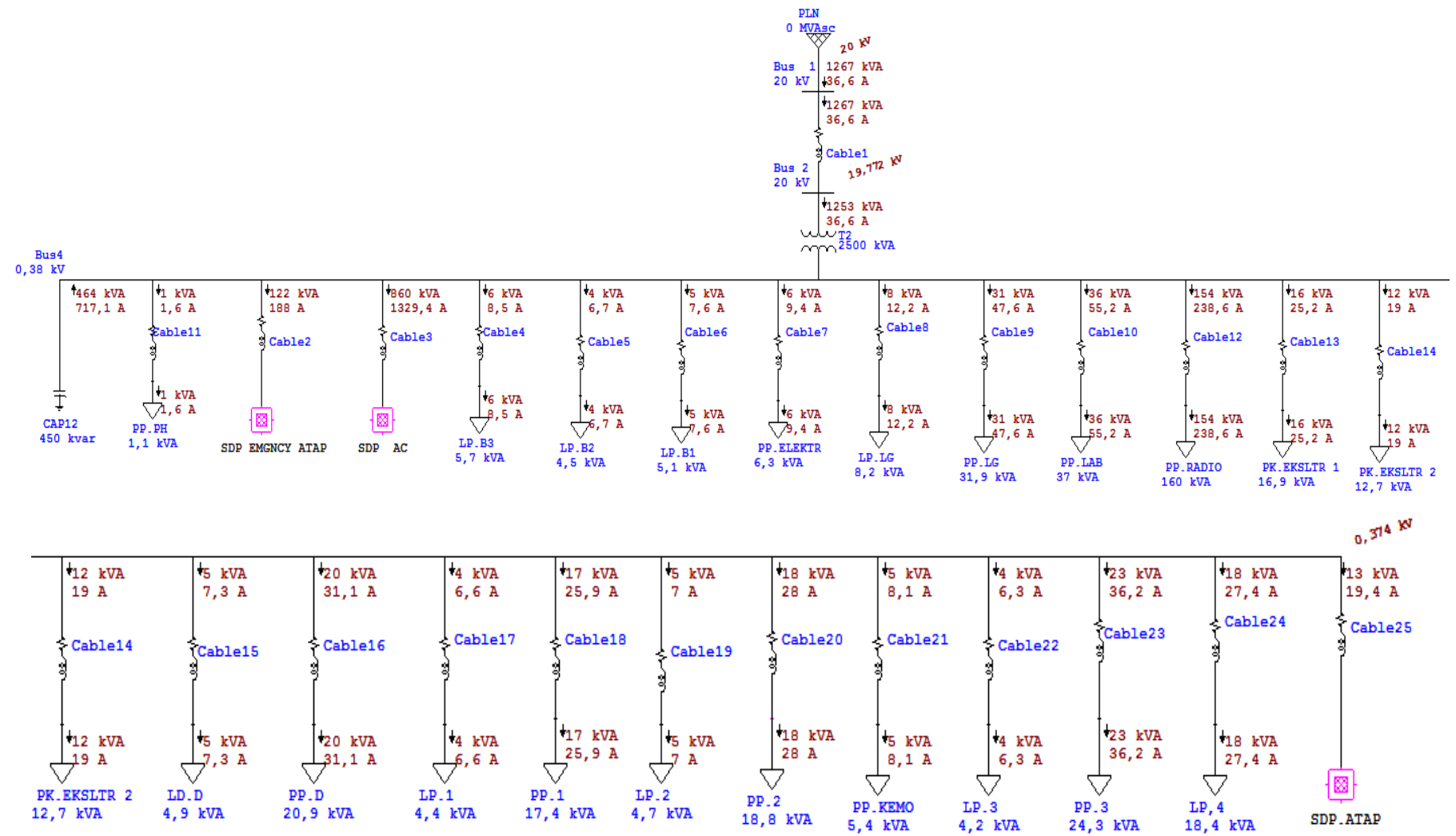

Fig. 6. Modeling LVMDP Load on ETAP after Installing Power Capacitors for Calculation of Electric Current and Apparent Power.

TABLE. III. POWER LOSSES BEFORE AND AFTER INSTALLATION OF BANK CAPACITOR

\begin{tabular}{|l|l|l|l|}
\hline \multirow{2}{*}{ No. } & \multirow{2}{*}{ Hospital Installation } & \multicolumn{2}{|l|}{ Power Losses } \\
\cline { 3 - 4 } & & $\mathrm{P}(\mathrm{kW})$ & $\mathrm{Q}(\mathrm{kVAR})$ \\
\hline 1. & Before installation of bank capacitor & 17.0 & 50.8 \\
\hline 2. & After installation of bank capacitor & -14.0 & 43.2 \\
\hline
\end{tabular}

TABLE. IV. HOSPITAL BUILDING INSTALLATION BEFORE AND AFTER INSTALLATION OF BANK CAPACITOR

\begin{tabular}{|c|c|c|c|c|c|c|c|c|c|c|c|}
\hline \multirow{3}{*}{ No. } & \multirow{3}{*}{ Components } & \multirow{2}{*}{\multicolumn{2}{|c|}{ Voltage $(\mathrm{kV})$}} & \multirow{2}{*}{\multicolumn{2}{|c|}{ Electric Currents (A) }} & \multicolumn{6}{|l|}{ Power } \\
\hline & & & & & & \multicolumn{2}{|c|}{ Reactive Power (kVAR) } & \multicolumn{2}{|c|}{ Active Power $(\mathrm{kW})$} & \multicolumn{2}{|c|}{ Apparent Power (kVA) } \\
\hline & & Before & After & Before & After & Before & After & Before & After & Before & After \\
\hline 1 & Busbar $20 \mathrm{kV}$ & 20 & 20 & 39.7 & 36.6 & 563 & 94 & 1252 & 1263 & 1373 & 1267 \\
\hline 2 & Busbar $0.38 \mathrm{kV}$ & 0.369 & 0.374 & 2088.5 & 2083.8 & 567 & 98 & 1235 & 1249 & 1359 & 1253 \\
\hline 3 & Busbar SDP Emergency & 0.368 & 0.373 & 189.5 & 188.0 & 64 & 64 & 103 & 103 & 121 & 122 \\
\hline 4 & Busbar SDP AC & 0.365 & 0.37 & 1340.3 & 1329.4 & 452 & 455 & 727 & 731 & 856 & 860 \\
\hline 5 & Busbar SDP Rooftop & 0.368 & 0.373 & 19.4 & 19.1 & 0 & 0 & 12 & 13 & 12 & 13 \\
\hline
\end{tabular}

\section{CONCLUSIONS}

After making improvements to the power factor by raising cos phi, which was initially from 0.73 to 0.9 , it can reduce the amount of reactive power $(\mathrm{kVAR})$, apparent power $(\mathrm{kVA})$, increase the active power $(\mathrm{kW})$, and cause a decrease in the load current. Thus it can supply power to more loads and can reduce the voltage drop. This condition also reduced the number of losses from the initial state of active power by 17 $\mathrm{kW}$ to $14 \mathrm{~kW}$ and reactive power before the installation of capacitors by $50.8 \mathrm{kVAR}$ to $43.2 \mathrm{kVAR}$. This fact shows that the higher the value of the power factor, the smaller the current flowing in the distribution network. This phenomenon dramatically affects electrical equipment, both cable size, electrical safety, and other electrical equipment. By increasing the power factor above 0.85, PLN will not provide compensation due to high $\mathrm{kVAR}$. Improving the power factor from 0.73 to 0.9 requires a bank capacitor to compensate for reactive power of $455 \mathrm{kVAR}$. However, the capacity of existing bank capacitors in the market is $50 \mathrm{kVAR}$, so the capacitor banks that will be installed to be $480 \mathrm{kVAR}$ are connected as many as 12 steps with each capacitor value of 50 kVAR. 


\section{ACKNOWLEDGMENT}

The authors gratefully acknowledge the contributions of the Directorate General of Development and Research Enhancement, Ministry of Research, Technology and Higher Education of the Republic of Indonesia, for funding this research.

\section{REFERENCES}

[1] L. Tang, W. Xu, C. Mu, "Analysis for step-size optimisation on MPPT algorithm for photovoltaic systems", IET Power Electronics, Vol. 10, No. 13, pp. 1647 - 1654, 2017.

[2] A. Jamal, R. Syahputra," UPFC Based on Adaptive Neuro-Fuzzy for Power Flow Control of Multimachine Power Systems", International Journal of Engineering Science Invention (IJESI), Vol. 2, No. 10, pp. 514, 2013.

[3] Syahputra, R., Soesanti, I., Ashari, M. (2016). Performance Enhancement of Distribution Network with DG Integration Using Modified PSO Algorithm. Journal of Electrical Systems (JES), 12(1), pp. 1-19.

[4] Syahputra, R., Robandi, I., Ashari, M. (2015). Performance Improvement of Radial Distribution Network with Distributed Generation Integration Using Extended Particle Swarm Optimization Algorithm. International Review of Electrical Engineering (IREE), 10(2). pp. 293-304.

[5] Syahputra, R., Robandi, I., Ashari, M. (2014). Optimization of Distribution Network Configuration with Integration of Distributed Energy Resources Using Extended Fuzzy Multi-objective Method. International Review of Electrical Engineering (IREE), 9(3), pp. 629639.

[6] H. Saadat, (1999). Power System Analysis, Singapore, McGraw-Hill, 1999.

[7] Syahputra, R. (2017). Distribution Network Optimization Based on Genetic Algorithm. Jurnal Teknologi, Journal of Electrical Technology UMY (JET-UMY), 1(1), pp. 1-9.

[8] Mujaahid, F., Fauzi, A.M., Syahputra, R., Putra, K.T., Purwanto, K. Potentials of Organic Waste Conversion in a Green Campus Concept. Journal of Electrical Technology UMY (JET-UMY), 1(4), pp. 183-188.

[9] Ahmed, J., Salam, Z. (2018). An Enhanced Adaptive P\&O MPPT for Fast and Efficient Tracking Under Varying Environmental Conditions, IEEE Transactions on Sustainable Energy, 9(3), pp. 1487 - 1496.

[10] Soesanti, I., Syahputra, R. (2016). Batik Production Process Optimization Using Particle Swarm Optimization Method. Journal of Theoretical and Applied Information Technology (JATIT), 86(2), pp. 272-278.
[11] Syahputra, R., Robandi, I., Ashari, M. (2015). PSO Based Multiobjective Optimization for Reconfiguration of Radial Distribution Network. International Journal of Applied Engineering Research (IJAER), 10(6), pp. 14573-14586.

[12] Hui, J.C.y., Bakhshai, A., Jain, P.K. (2016). An Energy Management Scheme With Power Limit Capability and an Adaptive Maximum Power Point Tracking for Small Standalone PMSG Wind Energy Systems, IEEE Transactions on Power Electronics, 31(7), pp. 4861 - 4875.

[13] Soedibyo, Ashari, M., Syahputra, R. (2014). "Power loss reduction strategy of distribution network with distributed generator integration", Proceeding of 2014 1st International Conference on Information Technology, Computer, and Electrical Engineering (ICITACEE) 2014, UNDIP Semarang, pp. 404 - 408.

[14] Jamal, A., Suripto, S., Syahputra, R. (2015). Multi-Band Power System Stabilizer Model for Power Flow Optimization in Order to Improve Power System Stability. Journal of Theoretical and Applied Information Technology (JATIT), 80(1), pp. 116-123.

[15] Syahputra, R., Soesanti, I. (2016). Application of Green Energy for Batik Production Process. Journal of Theoretical and Applied Information Technology (JATIT), 91(2), pp. 249-256.

[16] R.G. Andrei, M. Ahmed; H.K. Tumageanian, J. C. Smith. "World's first commercial bridge capacitor bank installation on the American Electric Power System", IEEE Transactions on Power Delivery, Vol. 16, No. 2, pp. 342-345, 2001.

[17] Jamal, A., Syahputra, R. (2016). Heat Exchanger Control Based on Artificial Intelligence Approach. International Journal of Applied Engineering Research (IJAER), 11(16), pp. 9063-9069.

[18] Syahputra, R., Soesanti, I. (2016). An Optimal Tuning of PSS Using AIS Algorithm for Damping Oscillation of Multi-machine Power System. Journal of Theoretical and Applied Information Technology (JATIT), 94(2), pp. 312-326.

[19] Syahputra, R., Soesanti, I. (2017). Modeling of Wind Power Plant with Doubly-Fed Induction Generator. Jurnal Teknologi, Journal of Electrical Technology UMY (JET-UMY), 1(3), pp. 126-134.

[20] R.G. Andrei, A.J.F. Keri, R.J. Albanese, P.B. Johnson, "Bridge capacitor bank installation concept reactive power generation in EHV systems", IEEE Transactions on Power System, Vol. 8, No. 4, pp. 1463 - 1470, 1993.

[21] K.D. McBee and M.G. Simões, "Evaluating the Long-Term Impact of a Continuously Increasing Harmonic Demand on Feeder-Level Voltage Distortion," IEEE Transactions on Industry Applications, Vol. 50, No. 3, May-June 2014, pp. 2142 - 2149.

[22] D. Shmilovitz, "On the definition of total harmonic distortion and its effect on measurement interpretation," IEEE Transactions on Power Delivery, Vol. 20, No. 1, Jan. 2005, pp. 526 - 528. 